Vol. 15 (2006): 77-88.

\title{
Decision support system for agricultural land use and fertilisation optimisation: a case study on barley production in Estonia
}

\author{
Alar Astover, Hugo Roostalu, Mati Mõtte, Indrek Tamm, Nikolay Vasiliev and Illar Lemetti \\ Estonian University of Life Sciences, Institute of Agricultural and Environmental Sciences, Department of Soil \\ Science and Agrochemistry, Tartu 51014,Kreutzwaldi 64,Estonia, e-mail: alar.astover@emu.ee
}

\begin{abstract}
The success of the decision support systems, developed within GIS with application of different models, depends on the quality of initial data and the models themselves as well as on the possibilities of their linking. The aim of the present study was to analyse the application of different agro-economic models in a computer-based decision support system, developed for optimisation of agricultural land use and fertilisation, on the example of barley production of Kullamaa rural municipality in Estonia. The algorithms used in the agronomical models were obtained from the regression analysis of numerous field experiments. The calculated new agronomical values serve as a basis for the application of economic models. GIS and modelling remain as two separate systems with the capacity for information exchange between them. Profitability of barley cultivation varied in a very broad range in the study area. The optimal fertiliser amounts established for each field allow increasing crop productivity in the region and at the same time preventing environmental pollution due to production intensification. The proposed decision support system can be further supplemented by several agro-economic models and implemented throughout Estonia.
\end{abstract}

Key words: barley, fertilisation, geographical information system, land use, decision making, risk factors, soil map

\section{Introduction}

The profitability and sustainability of agricultural production depends largely on the comprehensive knowledge of the quality of land as a means of production as well as on the consideration of it in the planning of land use in the whole region. Agriculture more than any other branch of production is influenced by various natural, anthropogenic and economic risk factors on which the profitability of production and preservation of the environment in rural areas depend. Suitable areas for agricultural use are determined by biophysical and socio-eco- 
nomic factors. Rational decision making can only be carried out through a multi-criterion evaluation of these factors. The prerequisites for optimal decision making are availability of reliable information and the ability to handle it. Natural resources are extremely variable on the spatial and temporal scales. The larger the spatial or temporal scale, the more complex will be the process of exploring and predicting agricultural land use (Stoorvogel and Antle 2001). Geographical information systems (GIS) are widely used for handling spatial information. The application of GIS in land use and fertilisation has been described in numerous papers (Rao et al. 2000, Voivontas et al. 2001, Kalogirou 2002, Sedogo et al. 2002, Rounsevell et al. 2003, Tianhong et al. 2003, Morari et al. 2004). Geographical information system is a highly useful tool for storing, processing and manipulating spatial databases. In order to expand the application of GIS in agriculture, different (agro-economic) models should be integrated in a GIS system. The success of the decision support systems (DSS), developed within GIS with the use of different models, depends on the quality of initial data and the models themselves as well as on the possibilities of their linking. Decision support systems are computer-based frameworks for integrating data and expert opinions with models, which enable finding different solutions when analysing a particular problem and by means of GIS, to make spatial recommendations (Fischer et al. 1996).

It is possible to proceed from available GIS maps and databases and to supplement them with suitable models to generate new values necessary for analysing a particular problem. Such an approach allows flexible optimisation of different activities: like land use planning (Matthews et al. 1999, Ceballos-Silva and Lopez-Blanco 2003) and allocation (Carsjens and Knaap 2002, Wang et al. 2004), fertilisation (Tianhong et al. 2003), biomass production (Voivontas et al. 2001), environmental protection (Aspinall and Pearson 2000), nutrient balances (Sacco et al. 2003), nature conservation (Geneletti 2004). One of the main reasons for the lack of model based DSS is that input values for models are unavailable or expensive or difficult to collect (Parker and Campion 1997).
In decision making for land use planning and utilisation of resources, a large-scale soil map and supplementary databases form an important component of DSS (Reintam et al. 2003). Supplementing digital soil maps with land use maps allows analysis of the production potential and the landuse suitability of each agricultural field. Besides the information drawn from soil databases, the knowledge of the agro-chemical characteristics of each agricultural field is needed, which serves as a basis for optimisation of fertiliser norms.

The aim of the present study was to analyse the application of different agro-economic models in a computer-based decision support system, developed for the optimisation of agricultural land use and fertilisation, on the example of barley production. Barley is the most important field crop in Estonia, accounting for $45-50 \%$ of the total area of cereals.

\section{Material and methods}

\section{Study area}

A GIS including database of soil properties was developed covering the fields (5,000 ha) of the arable land of Kullamaa rural municipality. Kullamaa rural municipality is located in western Estonia. Its total area is $224 \mathrm{~km}^{2}$ of which the agricultural area makes up $22 \%$. The average cultivation area of cereals per enterprise is 67 ha. In 19922000 , the actual average productivity of cereals in the studied area was $1.5 \mathrm{Mg} \mathrm{ha}^{-1}$ and the variation coefficient of the yield was $23 \%$. Inadequate application of fertilisers is among the main causes of the low and unstable yield. In the period 19962000, cereals received $39 \mathrm{~kg} \mathrm{NPK} \mathrm{ha}^{-1}$ in the form of mineral fertilisers and $3.8 \mathrm{Mg} \mathrm{ha}^{-1}$ organic fertilisers. Mineral fertilisers were only used in $46 \%$ and organic fertilisers in $6.4 \%$ of the total growth area of cereals. To ensure more efficient and stable cereal production, it is essential to optimise fertilisation and to provide location-based recommendations for it. 
Vol. 15 (2006): 77-88.

\section{The structure of a decision support system and data sources}

To develop agro-economic models necessary for the implementation of DSS, a complex database was created using the information of scientific dissertations, publications and reports; the results of variety comparison experiments; the databases of agro-meteorological stations; the data of the Animal Recording Centre; the databases of the institutions of nature and environmental conservation, the Statistical Office, the Land Board, the Agricultural Registries and Information Board, and the Agrochemical Service of Estonia. Such an up-todate analysis of the large-scale database, covering the whole agricultural production, allowed us to develop the agronomic and economic models of the productivity and yield quality of particular field crops as well as of the production and marketing of products of animal husbandry. This approach also allowed, on the basis of the models, to assess the degree of the probability and impact of natural and economic risk factors in case of different methods of land use and agricultural strategies.

A shortcoming of computer-based DSS in agriculture is often unavailability of required input data (Parker and Campion 1997). To overcome this disadvantage in the development of DSS, we proceeded from available vector maps and databases. The aim of this approach was the feasibility of optimisation of agricultural land use at different levels, making use of the materials collected by various state agencies and research institutions. Such an approach allows implementation of the developed DSS across the whole of Estonia.

The main component of the system is the map layer of the arable fields (Fig. 1). The initial data for each field used in agronomic models were soil quality points (on a 100-point scale), humus content (determined by Tjurin method), and content of available phosphorus and potassium (determined by Egner-Riehm double lactate method). The calculated new agronomical values serve as a basis for the application of economic models. The new agro-economic values for each field and the compiled thematic maps or tables can be used in deci- sion making processes. Proceeding from the calculated agro-economic characteristics, it is possible to assess the optimal use of each agricultural field as well as the development potential of the whole region. For this, is possible up-scale the modelling results from field-level to regional level (Saarikko 2000, Tan and Shibasaki 2003). Information flow for decision makers and stakeholders is possible from output data of DSS models or directly from input data layers. Non-spatial information flow (including expert opinions) to the DSS is essential to develop agronomic and economic models and to supplement the decision making process.

In the development of GIS, the software systems MapInfo Professional and MicroStation Geographics were used. There are several approaches to combine GIS with modelling (Sui 1998). In the current DSS, GIS and modelling are in a loose coupling category that integrates GIS with analytical models through the exchange of data files. Neither agronomic nor economic models are directly associated with GIS. This approach requires little investment in software development (Matthews et al. 1999). Fedra (1996) proposes an integrated framework in which GIS and modelling remain as two separate systems with the capacity for information exchange between them. The calculations based on the algorithms used in the models were made using MS Excel and the new values were then updated in GIS.

The polygons of the fields were mapped by the Estonian Agricultural Registry and Information Board (ARIB). Digitalisation is based on the ortho-photos obtained from the Estonian Land Board. Each agricultural field is supplied with a unique identification number, which allows joining the databases of ARIB in GIS. The databases of ARIB provide additional information for decision making.

Using GIS environment, topology analysis of the field layers and soil map polygons was performed (Fig. 1). The generated database with soil characteristics can provide input values for models used in DSS. For analysing the soils of agricultural land, a digital soil map (scale 1:10,000) was used. The scale 1:10,000 is appropriate for decision making at the field level (Avery 1987). In Estonia, 


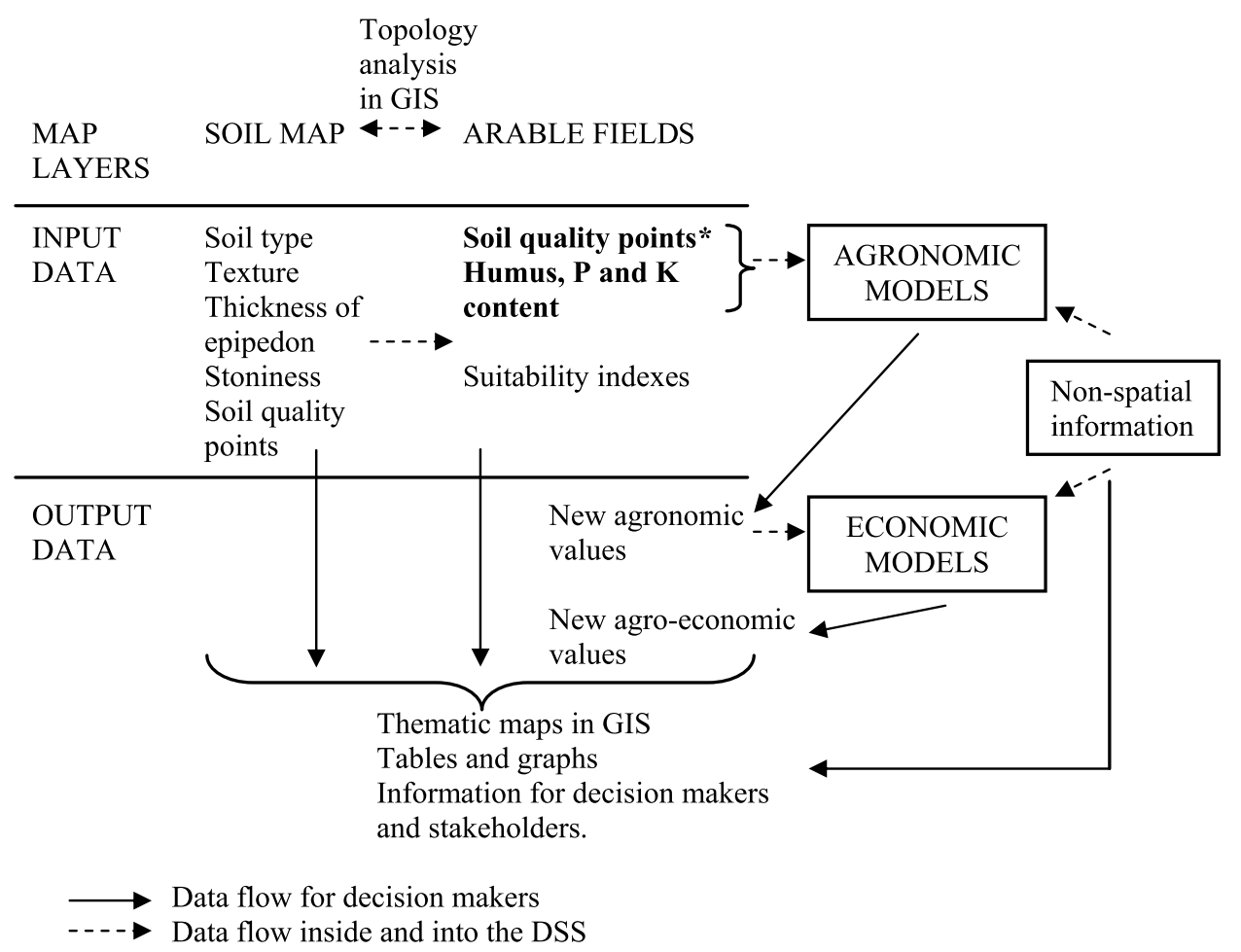

Fig. 1. Structure of the decision support system and linking of the models. * Field-specific input values applied in agronomic models in the current study are in bold.

digital soil maps, covering the whole territory, as well as maps of the lime and fertiliser requirements of arable soils have been compiled. The database supplementing the digital soil map includes the following data: soil type, texture abbreviation, thickness of the epipedon, classes of stoniness, and soil quality points. As most of the data in the soil database are in a string format, the application of these data in models for generating new values is limited. Further, the soil database should be definitely appended with quantitative parameters, which would provide prerequisites for its more extensive application.

Assessment of soil quality points is based on soil crop productivity: there is a linear relationship between quality point and crop yield. Soil quality points are usually determined for each soil-mapping unit and further it is possible to calculate average soil quality for each management unit. To assess the cultivation value of soils, the points of soil suitability indexes for selected field crops were also entered in the database (Fig. 1). The soil suitability index ( $0-10$ points) developed for the conditions of Estonia takes into account the productivity of different soils by the main crops (Valler 1973, Kõlli 1994).

The soil quality points and the data of humus content were drawn from the databases of the Land Board. The data of soil available phosphorus and potassium were obtained from the archives of the Estonian Agricultural Research Centre. As in the 1990s the determination of fertiliser requirement in Estonia practically stopped, the results of the last (in 1985-1989) nationwide determination were employed. This enabled the evaluation of soil nutrient requirement for the entire study area and, proceeding from this, to identify the possibilities of DSS application. In 2002 the state supported de- 
Vol. 15 (2006): 77-88.

termination of fertiliser requirement was restarted and the results of the current determination will be entered directly in the GIS. This serves as a solid basis for the implementation of the developed DSS for the optimisation of fertilisation throughout Estonia. Since one soil sample in both previous and current agro-chemical soil survey represents 3-5 ha, then these data are suitable for modelling and decision making at a field-scale.

\section{Agronomic and economic models}

Integration of the initial data, related to each agricultural field, in agronomic models enables calculation of new agronomic values such as productivity, effectiveness of fertilisers, etc. The algorithms used in the agronomical models were obtained from the regression analysis of numerous different field experiments. The relationships between barley yield and soil properties and fertilisation were established using a database containing the results of more than 600 field experiments conducted in Estonia.

The yield of barley was found for the non-fertilised variant and for the fertilised variant. In case of the non-fertilised variant the yield depends on soil quality. To simulate non-fertilised yield of barley depending on the soil fertility and to estimate weather related variability the following regression equation $\left(\mathrm{r}^{2}=0.84 ; \mathrm{SE}=0.318 ; \mathrm{P}<0.000\right)$ was applied:

$$
\begin{aligned}
Y_{0}= & 1.288-0.0343 S Q-0.0383 P+ \\
& 0.0002811 P^{2}-0.00000001635 P^{4}
\end{aligned}
$$

where $Y_{0}$ is the yield for non-fertilised barley $(\mathrm{Mg}$ ha $\left.^{-1}\right), S Q$ is soil quality points and $P$ is probability (\%). In the current study probability at $50 \%$ is used, which represents yield as an average over many years.

In the fertilised variant the yield includes also increase from the addition of an economically effective norm of NPK. The use of an agronomically effective fertiliser norm ensures a maximum grain yield and the use of an economically effective fer- tiliser norm ensures the highest profit. The agronomically and economically effective fertiliser norms for barley are calculated from the quadratic yield response curves for different soil nutrient supply levels $\left(\mathrm{r}^{2}=0.93-0.99 ; \mathrm{SE}=0.1-0.15 ; \mathrm{P}<\right.$ $0.05)$. A general form of the quadratic yield response equation is the following:

$$
Y=a_{0}+a_{1} x-a_{2} x^{2}
$$

where $Y$ is the yield $\left(\mathrm{Mg} \mathrm{ha}^{-1}\right)$ and $x$ is amount of fertiliser $\left(\mathrm{kg} \mathrm{ha}^{-1}\right)$.

The agronomically effective amount of fertiliser $\left(\mathrm{kg} \mathrm{ha}^{-1}\right)$ is calculated as follows:

$$
X a g r=\frac{a_{1}}{2 a_{2}}
$$

and the economically effective amount of fertilizer $\left(\mathrm{kg} \mathrm{ha}^{-1}\right)$ is calculated as follows:

$$
\text { Xecon }=\frac{a_{1}\left(P_{y}-C_{h}\right)-C_{f}}{2 a_{2}\left(P_{y}-C_{h}\right)}
$$

where $P_{y}$ is the price of the yield ( $\left.€ \mathrm{Mg}^{-1}\right), C_{f}$ is the cost of fertilisation $\left(€ \mathrm{~kg}^{-1}\right)$ and $C_{h}$ is the cost of harvesting $\left(€ \mathrm{Mg}^{-1}\right)$.

To calculate the profitability of barley cultivation $(R t, \%)$, we used the following formula:

$$
R t=\left[\left(\frac{P_{y} Y}{C_{f} x+C_{h} Y+C_{0}}\right)-1\right] * 100
$$

where $C_{o}$ denotes all other production expenses ( $€$ $\mathrm{ha}^{-1}$ ) such as salaries, depreciation etc.

To estimate the effectiveness of fertilisers, depending on soil humus content, and the effect of climatic conditions, the following regression equation $\left(r^{2}=0.68 ; \mathrm{SE}=5.98 ; \mathrm{P}<0.000\right)$ was solved:

$$
\begin{aligned}
Y_{N 60}^{\prime}= & 38.649-1.744 H-0.487 P \\
& +0.003323 P^{2}-0.0000001677 P^{4}
\end{aligned}
$$

where $Y^{\prime}{ }_{N 60}$ is average effectiveness $\left(\mathrm{kg} \mathrm{kg}^{-1} \mathrm{~N}^{-1}\right)$ of the nitrogen fertiliser norm $\mathrm{N}_{60}, H$ is soil humus content (\%) and $P$ is probability (\%).

To calculate economically effective rates, the cost of fertilisation and the harvesting costs of yield increase, as well as the returns from yield increase, are considered. Depending on soil humus content and the available content of $\mathrm{P}$ and $\mathrm{K}$, the 
effective fertiliser norms were calculated for each field.

In this study a simple farm economic model is used. The profit in barley cultivation is calculated as the difference between gross income and gross costs. Profitability in percentages describes the ratio of the profit to the gross costs. In the economic calculations, $109 € \mathrm{Mg}^{-1}$ was taken as the selling price of barley $\left(P_{y}\right), 19 € \mathrm{Mg}^{-1}$ as the harvesting

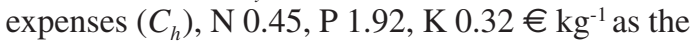
fertilisation expenses $\left(C_{f}\right)$ and $160 € \mathrm{ha}^{-1}$ as the other production expenses $\left(C_{o}\right)$. When developing the economic model, agricultural subsidies were excluded.

\section{Results and discussion}

\section{Soil resources}

The soils of the study area are dominated by different gleysoils (43.5\%) among which the proportion of Mollic Gleysols is the largest (Table 1). The share of automorphic and gleyic Calcaric Cambisols is also appreciable. Regarding soil texture, the most common texture is sandy loam $(56.1 \%)$.
Heavy texture occurs mainly in Mollic Gleysols. Peat soils account for $8.3 \%$ of arable land in the area. Because of the large proportion of hydromorphic soils, the state of drainage has become an important criterion for soil fertility and soil suitability. The area not requiring drainage makes up $21.6 \%$. A total of $62 \%$ of arable land is drained. As in the 1990s investments in land amelioration were minimal, it can be supposed that the condition of the former drainage systems has considerably deteriorated.

The average quality of all arable land in Estonia is 39 points. Average field soil quality in study area is 37 points. In different fields, soil quality ranges between $22-52$ points. The area with very low soil quality ( $<30$ points) makes up $9.5 \%$ (Table 2). The share of soils with low humus content in the study area is small. The fields with soil humus content less than $3 \%$ only account for $8.6 \%$, while humus-poor soils (humus content less than $2 \%$ ) are absent. The fields with low soil available phosphorus and potassium account for 17.1 and $13.9 \%$, respectively. Of all arable land, less than one-fourth is characterised by soils with high phosphorus and potassium content.

To assess soil suitability for the study area, the database was supplemented with soil suitability indexes (scale 0-10 points) according to different

Table 1. Soil composition of arable land in Kullamaa rural municipality.

\begin{tabular}{|c|c|c|c|c|c|c|}
\hline \multirow[t]{2}{*}{ Soil group by WRB* } & \multirow[b]{2}{*}{$\%$} & \multicolumn{5}{|c|}{ Soil texture, $\%$} \\
\hline & & Sand & Sandy loam & Loam & Clay & Peat \\
\hline Fluvisols & 1.3 & & 2.8 & 46.5 & 25.0 & 25.7 \\
\hline Calcaric Cambisols & 16.9 & 2.0 & 10.4 & 8.6 & & \\
\hline Gleyic-Calcaric Cambisols & 19.1 & 0.3 & 2.6 & 97.1 & & \\
\hline Rendzic Leptosols & 1.0 & & 0.8 & 99.2 & & \\
\hline Mollic Gleysols & 35.7 & 4.1 & 7.5 & 26.1 & 61.8 & 0.5 \\
\hline Calcari-Skeletic, Dystric, etc. Gleysols & 7.8 & 15.2 & 5.0 & 60.9 & 1.9 & \\
\hline Mollic Cambisols, Cutanic Luvisols & 2.4 & 13.1 & 24.5 & 62.4 & & \\
\hline Gleyic Cambisols and Luvisols & 7.4 & 3.4 & 9.9 & 76.3 & 10.3 & \\
\hline Albeluvisols & 0.2 & 100 & & & & \\
\hline Histosols & 8.3 & & & & & 100 \\
\hline Total & 100 & 3.8 & 6.7 & 56.1 & 24.6 & 8.8 \\
\hline
\end{tabular}

* The names of the soil groups are given according to the system of World Reference Base for Soil Resources 
Vol. 15 (2006): 77-88.

Table 2. Soil quality and humus content of arable land in the study area.

\begin{tabular}{lcc}
\hline Criteria & Intervals & Distribution, \% \\
\hline Soil quality & $<30$ & 9.5 \\
points & $31-35$ & 33.6 \\
& $36-40$ & 21.7 \\
& $41-45$ & 24.3 \\
& $46-52$ & 10.9 \\
Soil humus & $2.0-3.0$ & 8.6 \\
content, \% & $3.1-4.0$ & 37.0 \\
& $4.1-5.0$ & 34.3 \\
& $5.1-8.0$ & 1.4 \\
& $>12.0$ & 18.7 \\
\hline
\end{tabular}

Table 3. Soil suitability index for barley and field grasses for arable land in the study area.

\begin{tabular}{lrrrrrrr}
\hline Crop & \multicolumn{6}{c}{ Soil suitability index, \% } \\
\cline { 2 - 8 } & \multicolumn{1}{c}{4} & \multicolumn{1}{c}{5} & \multicolumn{1}{c}{6} & \multicolumn{1}{c}{7} & \multicolumn{1}{c}{8} & 9 & 10 \\
\hline Spring barley & 12.9 & 15.7 & 6.6 & 35.3 & 0.9 & 25.0 & 3.7 \\
Field grasses & 4.1 & 0.0 & 12.1 & 31.9 & 34.8 & 12.6 & 4.5 \\
\hline
\end{tabular}

crops. The higher the soil suitability index, the more suitable is this soil for cultivating a particular crop. The total area of the soils with a high cultivation value (9-10 points) for barley accounts for $28.7 \%$ (Table 3). At the same time, it should be taken into account that the area of the soils with a low cultivation value for barley production is large. However, the soils of the study area are relatively favourable for cultivation of field grasses, for which lands with a cultivation value higher than 6 points constitute $95.9 \%$.

\section{Effective norms of mineral fertilisers}

Agronomically effective fertiliser norms for barley, ensuring a maximum yield, depend on soil fertiliser requirement and vary in very large limits in the region: maximum up to $103 \mathrm{~kg} \mathrm{ha}^{-1}$ for nitrogen, and $27 \mathrm{~kg} \mathrm{ha}^{-1}$ and $60 \mathrm{~kg} \mathrm{ha}^{-1}$ for phosphorus and potassium, respectively. Effective fertiliser rates decline with increasing soil NPK supply. Soil $\mathrm{N}$ supply is evaluated according to soil humus content. As there is strong correlation between total soil nitrogen content and soil humus content $\left(\mathrm{r}^{2}=\right.$ $0.97 ; \mathrm{SE}=0.019 ; \mathrm{P}<0.000)$, it is possible to estimate the need for nitrogen fertiliser proceeding from soil humus content (Roostalu et al. 2003). For each arable field, agronomically and economically effective norms of nitrogen fertiliser were calculated on the basis of soil humus content (Fig. 2 ). To generate such an equation, previously effective fertiliser norms were determined for several soil nutrient supply levels. Although use of agronomically effective fertiliser norms ensures a maximum yield, this practice is not economically justi-
Fig. 2. Agronomically (Nagr) and economically (Necon) effective nitrogen fertiliser norms for barley depending on soil humus content.

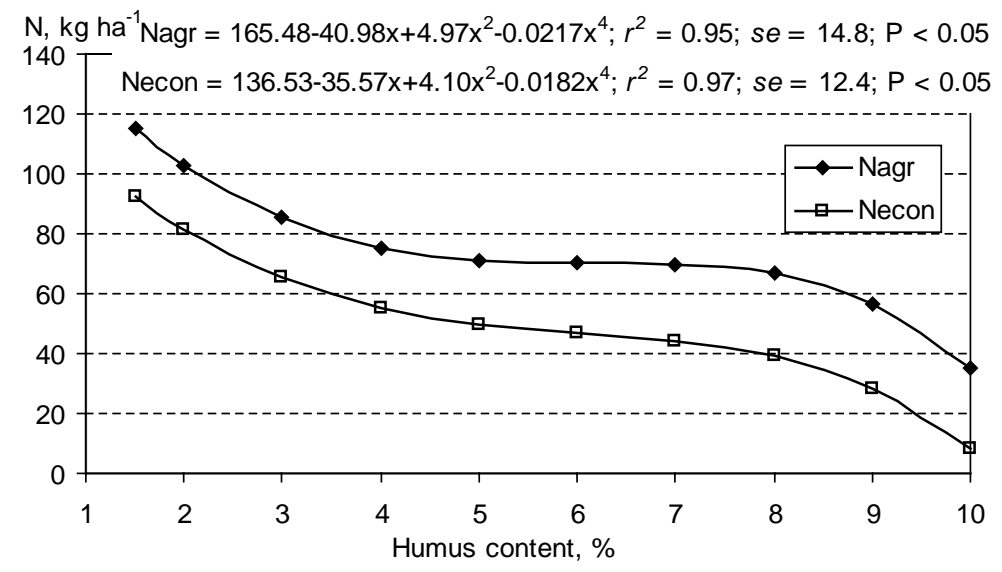


fied, as at a certain point the profit gained from an additional amount of fertiliser is lower than the extra costs. On soils whose humus content is higher than $10.2 \%$ it is unprofitable to apply nitrogen fertilisers for barley. Field experiments conducted with barley in Canada have shown that the net value of returns from $\mathrm{P}$ fertilisation increased with increasing $\mathrm{P}$ rate up to approximately $23 \mathrm{~kg} \mathrm{P} \mathrm{ha}^{-1}$ (Nyborg et al. 1999).

Compared with the agronomically effective fertiliser norms, the economically effective fertiliser norms, which guarantee a maximum profit in barley production, are $23 \%$ lower for N, $12 \%$ lower for $\mathrm{K}$ and as much as $59 \%$ lower for $\mathrm{P}$ (owing to the high prices of $\mathrm{P}$ fertiliser). Economically effective $\mathrm{N}$ norms range from 50 to $60 \mathrm{~kg} \mathrm{ha}^{-1}$ on $67.1 \%$ of agricultural land (Fig. 3). As the soils of the study area are largely humus-rich, the effectiveness of nitrogen fertilisers and their optimal amounts remain relatively low. However, at the same time, it is not economically reasonable to use nitrogen fertilisers for barley on $18.7 \%$ of the land.

Field-specific fertiliser recommendations will increase the profit and the nutrient use efficiency as well as will reduce negative impacts on the environment (Sacco et al. 2003, Brown et al. 2005). An excess of $\mathrm{N}$ and $\mathrm{P}$ can lead to eutrophication and to groundwater pollution (Öborn et al. 2003). The fertiliser norms found on the basis of soil fertiliser requirement for barley production in a particular region are also consistent with environmental and legislative restrictions. The developed DSS allows improving the level of crop productivity in the region and at the same time preventing pollution of the environment due to fertilisation. Proceeding from the soil database, it is possible to establish an agro-economically and environmentally grounded fertiliser norm for each field. Application of such an approach would be especially useful in areas with Nitrate Vulnerable Zones, which are located in regions with intensive agriculture in Estonia.

The effectiveness of fertilisation depends to a large extent on, besides soil properties, meteorological conditions. On the basis of all field trials conducted to date, it can be calculated that in case

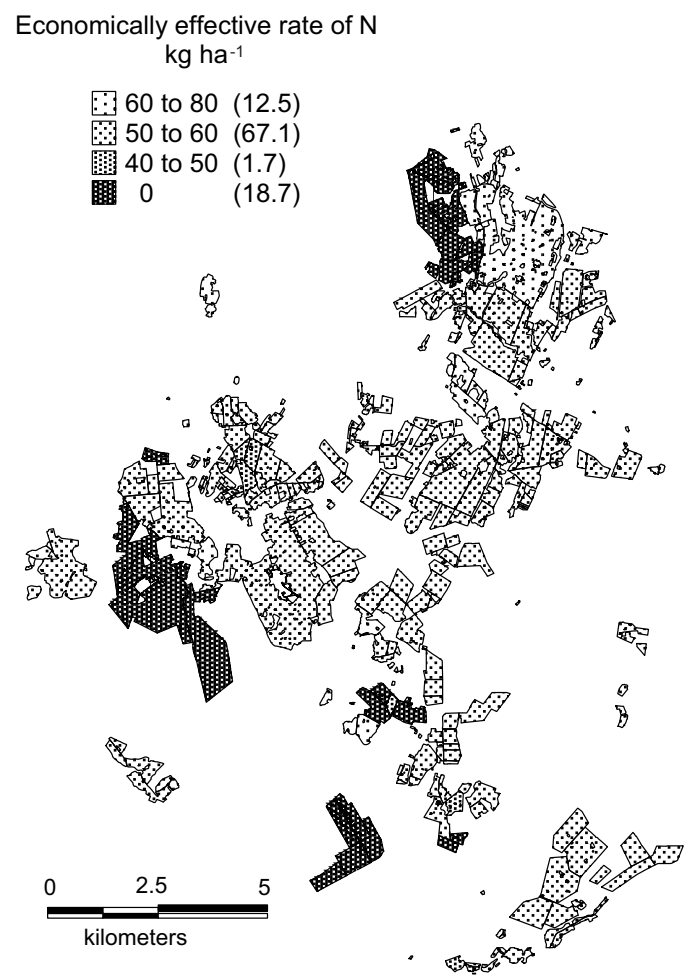

Fig. 3. Economically effective norms of $\mathrm{N}$ for barley in the fields of arable land in Kullamaa rural municipality. The number in brackets for each denoted range shows the proportion $(\%)$ of this range in the area.

of application of the $\mathrm{N}_{60}$ fertiliser norm for intensive barley varieties on moderately moist soils, with soil humus content ranging between 2 and $4 \%$, yield increase is $15-18 \mathrm{~kg} \mathrm{~N} \mathrm{~kg}^{-1}$. In highly favourable years as much as $25-30 \mathrm{~kg}$ of grain can be obtained, with a probability of $10-20 \%$, at the expense of $1 \mathrm{~kg}$ of nitrogen (Fig. 4). However, on gleyic and gley soils, richer in humus, this amount of nitrogen can lead to the lodging of the crop and to yield decrease 1-2 years out of ten (Roostalu et al. 2003).

To assess the weather related risk of fertilisation in barley production, the probability of the profit gained from fertilisation was calculated for the $\mathrm{N}_{60}$ fertiliser norm. This fertiliser norm is well consistent with the economically effective amount 
Vol. 15 (2006): 77-88.

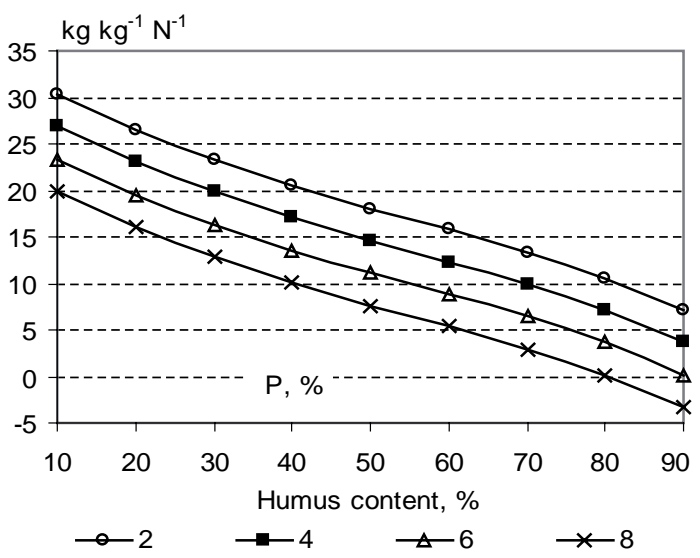

Fig. 4. Probability (P, \%) of the effectiveness $\left(\mathrm{kg} \mathrm{N} \mathrm{kg}^{-1}\right)$ of the $\mathrm{N}_{60}$ fertiliser norm depending on soil humus content.

found for the region. To ensure profit from fertilisation, the average efficiency of $\mathrm{N}_{60}$ must be higher than $5 \mathrm{~kg} \mathrm{~N} \mathrm{~kg}^{-1}$. The probability of gaining an economic profit with the application of the $\mathrm{N}_{60}$ fertiliser norm was in $79.6 \%$ of the studied area higher than $80 \%$, i.e. in eight years out of ten. In the remaining area, however, the agro-economic risk with the use of this particular $\mathrm{N}$ fertiliser norm was very high due to pedo-climatic conditions. As in some fields the probability of profitable fertilisation is minimal even at low $\mathrm{N}$ rates, it is crucial to provide field-specific fertilisation recommendations.

\section{Profitability of barley cultivation}

The yield of barley, the effectiveness of fertilisers and the profitability of barley production depend on soil fertility, weather conditions during growth, soil fertiliser requirement, amount of the fertilisers used and their cost and on the price of the crop. It depends as well on the possibilities of converting the yield into the output of animal production and its price and also on other production expenses and factors. With non-application of fertilisers, the barley yield obtained at the expense of soil fertility remains in the range of 0.7 to $1.8 \mathrm{Mg} \mathrm{ha}^{-1}$. Depend- ing on climatic conditions, the barley yield without fertilisation varies more when soil is less fertile. On poor soils, estimated at less than 30 quality points, the average barley yield is only $1 \mathrm{Mg} \mathrm{ha}^{-1}$, while in unfavourable years the crop may practically fail altogether. With the use of economically effective amounts of NPK fertilisers, the barley yield in the study area ranges from 1.0 to $4.3 \mathrm{Mg}$ $\mathrm{ha}^{-1}$. The average yield in case of the fertilised variant is $2.6 \mathrm{Mg} \mathrm{ha}^{-1}$. The actual farm yield of cereals in the study region is $42 \%$ lower. Thus the proposed DSS provides prerequisites for optimisation of barley fertilisation and for increasing the effectiveness of crop production in general. The average yield of spring cereals, obtained in variety comparison tests, is about 4-5 $\mathrm{Mg} \mathrm{ha}^{-1}$. At present approximately only $35-50 \%$ of the potential yield of cereals is obtained in Estonia (Roostalu et al. 2001).

Depending on soil properties, the profitability of barley cultivation varied in a very broad range in the study area (Fig. 5). In the current market situation barley production is not economically profitable on $28.3 \%$ of agricultural land. On the other hand, the profitability of barley production on $35.3 \%$ of agricultural land is higher than $20 \%$. Visualisation of the results by means of thematic maps enables to clearly present spatial variability in the profitability of barley production at the level of the region, farm or field. The compiled thematic maps can be used in field-specific decision making and in allocation of barley production. Farmers can use field-specific profitability data with other criteria for crop rotation planning and for strategic decisions but presented DSS do not make decisions, rather it contribute knowledge that is used in decision making process. Outputs from DSS are also applicable for development plans of local municipalities and for identifying less favoured areas (LFA) requiring additional subsidy schemes. The identification of LFA areas in Estonia took account of weighted average soil quality point for each rural municipality as one of the criteria. The proposed DSS can provide information for more precise spatial differentiation of LFA areas.

As the market of agricultural products is unstable, production is related to high economic risks. 
Profitability (\%) of barley cultivation

20 to 54 (35.3)

10 to $20(22.9)$

0 to $10(13.5)$

聞 -42 to 0 (28.3)

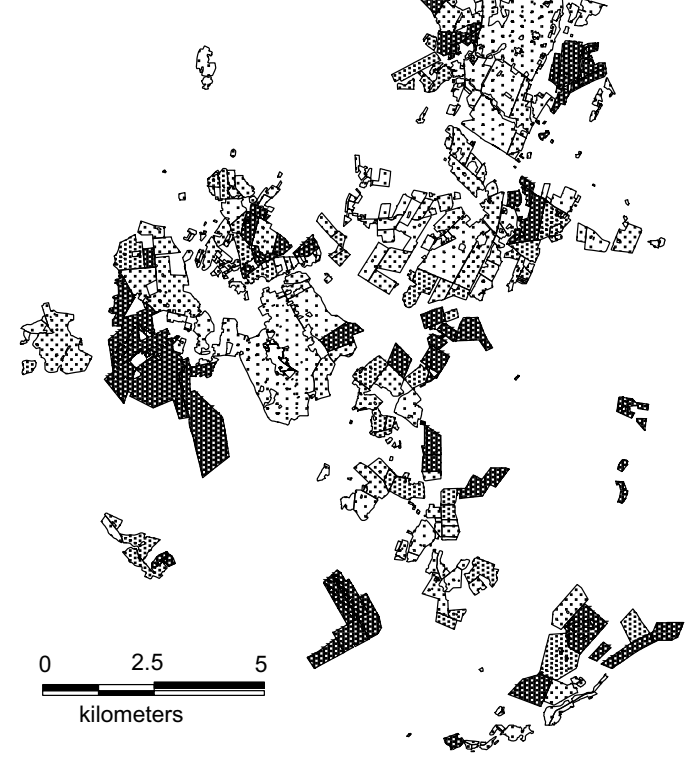

Fig. 5. Profitability of barley cultivation in the fields of arable land in Kullamaa rural municipality. The number in brackets for each denoted range shows the proportion (\%) of this range in the area.

The instability of the prices for agricultural products is the main factor, which influences the income of producers and the sustainability of the agricultural sector. According to the data from the
Estonian Institute of Economic Research, the farmgate price of barley was extremely unstable in the period 1999-2004. The variation coefficient of the farm-gate prices of fodder barley, the cereal with the highest production capacity, was $18 \%$. The price of fodder barley was lower than $90 € \mathrm{Mg}^{-1}$ for $49 \%$ of the months in the period 1999-2004 and exceeded $120 € \mathrm{Mg}^{-1}$ for only a short time (4\%). Although the price of food barley was somewhat higher, it has no significant effect on the economic results of the whole sector of cereal production because of the small market size. As an average for the period 1999-2003, fodder barley accounted for $79 \%$ and food barley accounted for only $8 \%$ of the total consumption.

In case barley is sold at low prices $\left(90 € \mathrm{Mg}^{-1}\right)$ the proportion of profitable land would be $28 \%$. With a $10 €$ increase in the price, already $59 \%$ of arable land would yield profit (Fig. 6). However, even at high selling prices of barley, the cultivation of this cereal would be unprofitable in some fields. In the production of barley without mineral fertilisers, its selling price must be considerable higher in order to gain a profit equal to that gained with application of economically effective fertiliser norms. In the production of non-fertilised barley, its selling price must be more than 1.5 times higher in order to achieve profitability comparable to that gained from the production of fertilised barley. In the current market situation of Estonia, it is unrealistic to gain such a high price-premium for organic barley. Thus it is evident that the profitability of

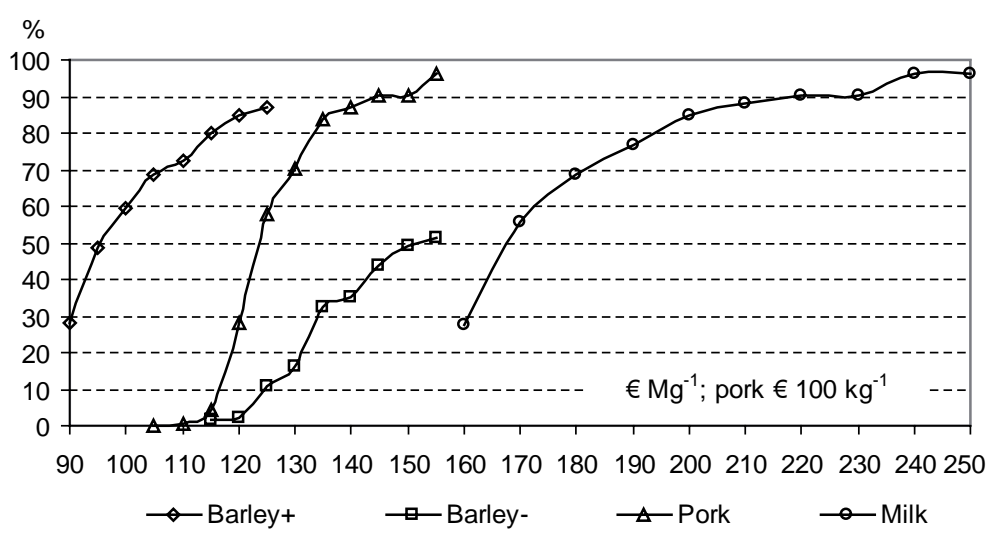

Fig. 6. The proportion of profitable land $(\%)$ in different conditions of barley production and marketing depending on the selling price of production. Barley+ with economically effective mineral NPK and barley- without fertilisation. 
Vol. 15 (2006): 77-88.

organic farming depends first of all on the level of additional subsidies.

Besides direct sale, it is possible to convert barley into animal products, assessing the economic suitability of agricultural land on the basis of the profit gained from, e.g. pork or milk production. To gain profit from at least $70 \%$ of arable land, the selling price of barley must be higher than $106 €$ $\mathrm{Mg}^{-1}$. In order to gain the same profit from pork production, the price of pork must be higher than $130 € 100 \mathrm{~kg}^{-1}$ and in milk production the price of milk must be higher than $181 € \mathrm{Mg}^{-1}$ (Fig. 6). Considering the current market situation, the required price is most definitely guaranteed in milk production. Although in case of converting barley at current milk prices the share of unprofitable land would be less than $10 \%$, it should be taken into account that when the cost price of barley exceeds the market price of fodder barley, the profitability of milk production will decrease significantly. If the cost price of self-produced barley exceeds the market price of fodder barley then it is not profitable to grow barley for feed. In this case, it is more profitable for the milk producer to use imported concentrated feed than to produce fodder barley himself.

\section{Conclusions}

Agro-economic analysis of land use for different field crops and use of digital maps allow assessing and comparing the effectiveness of the means of production as well as its profitability. Hence estimation of soil fertility and production optimisation of an enterprise or a region should include a complex agro-pedological and economic analysis of land use, of the possibilities of specialisation of production and application of different technologies as well as of the environmental aspects. Assessment and optimisation of land use and of the production potential of agriculture with GIS can serve as a basis not only for drawing up regional development plans but also, and primarily, for advisory service, for advanced education and for de- velopment of national agricultural and land use policies. The present study provides some examples of the possibilities of agricultural land use and fertilisation optimisation in one region. The optimal fertiliser amounts established for each field allow increasing crop yields and at the same time preventing environmental pollution due to production intensification. The proposed extensible DSS should be further supplemented with different agro-economic and ecological models and can be used as one tool in knowledge-based decision making processes throughout Estonia.

Acknowledgements. The study was supported by the Estonian Science Foundation grant No. 4819. We would like to thank Estonian Land Board, Estonian Agricultural Research Centre, Estonian Agricultural Registers and Information Board and Ltd. E.O.Map for their collaboration during this research.

\section{References}

Aspinall, R. \& Pearson, D. 2000. Integrated geographical assessment of environmental condition in water catchments: Linking landscape ecology, environmental modelling and GIS. Journal of Environmental Management 59: 299-319.

Avery, B.W. 1987. Soil survey methods: a review. Technical Monograph No. 18. Silsoe: Soil Survey \& Land Resource Centre. $86 \mathrm{p}$.

Brown, L., Scholefield, D., Jewkes, E.C., Lockyer, D.R. \& del Prado, A. 2005. NGAUGE: A decision support system to optimise $\mathrm{N}$ fertilisation of British grassland for economic and environmental goals. Agriculture, Ecosystems and Environment 109: 20-39.

Carsjens, G.J. \& Knaap, W. 2002. Strategic land-use allocation: dealing with spatial relationships and fragmentation of agriculture. Landscape and Urban Planning 58: 171-179.

Ceballos-Silva, A. \& Lopez-Blanco, J. 2003. Delineation of suitable areas for crops using a Multi-Criteria Evaluation approach and land use/cover mapping: a case study in Central Mexico. Agricultural Systems 77: 117136.

Fedra, K. 1996. Distributed models and embedded GIS. In: Goodchild, M.F. (ed.). GIS and Environmental Modelling: Progress and Research Issues. GIS World Books, Fort Collins, p. 413-417.

Fisher, M.M., Scholten, H.J. \& Unwin, D. 1996. Geographic information systems, spatial data analysis and spatial modelling: an introduction. In: Fisher, M.M. et al. (eds.). Spatial analytical perspectives on GIS. Taylor and Francis. p. 3-19. 
Astover, A. et al. Decision support system for agricultural land use

Geneletti, D. 2004. A GIS-based decision support system to identify nature conservation priorities in an alpine valley. Land Use Policy 21: 149-160.

Kalogirou, S. 2002. Expert systems and GIS: an application of land suitability evaluation. Computers, Environment and Urban Systems 26: 89-112.

Kõlli, R. 1994. Suitability of soils for use and agrogroups. Estonian Agricultural University, Tartu. 85 p. (in Estonian).

Matthews, K.B., Sibbald, A.R. \& Craw, S. 1999. Implementation of a spatial decision support system for rural land use planning: integrating geographic information system and environmental models with search and optimisation algorithms. Computers and Electronics in Agriculture 23: 9-26.

Morari, F., Lugato, E. \& Borin, M. 2004. An integrated nonpoint source model-GIS system for selecting criteria of best management practices in the Po Valley, North Italy. Agriculture, Ecosystems and Environment 102: 247262.

Nyborg, M., Malhi, S.S., Mumey, G., Penney, D.C. \& Laverty, D.H. 1999. Economics of phosphorus fertilization of barley as influenced by concentration of extractable phosphorus in soil. Communications in Soil Science and Plant Analyisis 30, 11-12: 1789-1795.

Öborn, I., Edwards, A.C., Witter, E., Oenema, O., Ivarsson, K., Withers, P.J.A., Nilsson, S.I. \& Richert-Stinzing, A. 2003. Element balances as tool for sustainable nutrient management: a critical appraisal of their merits and limitations within an agronomic and environmental context. European Journal of Agronomy 20: 211-225.

Parker, C.G. \& Campion, S. 1997. Improving the uptake of decision support systems in agriculture. In: First European Conference for Information Technology in Agriculture, Copenhagen. Updated 26 May 1997. Cited 12 Nov 2005. Available on the Internet: http://www.dina. dk/efita-conf/program/paperspdf/iv_a_2.pdf

Rao, M.N., Waits, D.A. \& Neilsen, M.L. 2000. A GIS-based modelling approach for implementation of sustainable farm practices. Environmental Modelling \& Software 15: 745-753.

Reintam, L., Kull, A., Palang, H. \& Rooma, I. 2003. Largescale soil maps and supplementary database for land use planning in Estonia. Journal of Plant Nutrition and Soil Science 166: 225-231.
Roostalu, H., Astover, A. \& Mõtte, M. 2001. Yield potential and its realization. Transactions of Estonian Agricultural University 212: 25-32. (in Estonian)

Roostalu, H., Astover, A. \& Tamm, I. 2003. Agroeconomic criteria of application of nitrogen fertilizers. Proceeding of 14th CIEC International Symposium of Fertilizers, Debrecen. p. 49-56.

Rounsevell, M.D.A., Annetts, J.E., Audsley, E., Mayr, T. \& Reginster, I. 2003. Modelling the spatial distribution of agricultural land use at the regional scale. Agriculture, Ecosystems and Environment 95: 465-479.

Saarikko, R.A. 2000. Applying a site based crop model to estimate regional yields under current and changed climates. Ecological Modelling 131: 191-206.

Sacco, D., Bassanino, M. \& Grignani, C. 2003. Developing a regional agronomic information system for estimating nutrient balances at larger scale. European Journal of Agronomy 20: 199-210.

Sedogo, L.G. \& Groten, S.M.E. 2002. Integration of local participatory and regional planning: A GIS data aggregation procedure. Geojournal 56: 69-81.

Stoorvogel, J.J. \& Antle, J.M. 2001. Regional land use analysis: the development of operational tools. Agricultural Systems 70: 623-640.

Sui, D.Z. 1998. GIS-based urban modelling: practices, problems, and prospects. International Journal of Geographical Information Science 12, 7: 651-671.

Tan, G. \& Shibasaki, R. 2003. Global estimation of crop productivity and the impacts of global warming by GIS and EPIC integration. Ecological Modelling 168: 357-370.

Tianhong, L., Yanxin, S. \& An, X. 2003. Integration of large scale fertilizing models with GIS using minimum unit. Environmental Modelling and Software 18: 221-229.

Valler, V. 1973. Evaluation of arable land from the point of cultivating main crops. Socialistic Agriculture 20: 925930. (in Estonian).

Voivontas, D., Assimacopoulus, D. \& Koukis, E.G. 2001. Assessment of biomass potential for power production: a GIS based method. Biomass and Bioenergy 20: 101112.

Wang, X., Yu, S. \& Huang, G.H. 2004. Land allocation based on integrated GIS-optimization modelling at watershed level. Landscape and Urban Planning 66: 61-74. 